\title{
Oncocytoma of the Parotid Gland: A Case Report and Review of the Literature
}

\author{
Ilson Sepúlveda ${ }^{a, b} \quad$ Enrique Platín ${ }^{c} \quad$ M. Loreto Spencer ${ }^{d}$ \\ Pablo Mucientes $^{d} \quad$ Michael Frelinghuysen $^{\mathrm{e}}$ Pablo Ortega $^{f}$ \\ David Ulloa ${ }^{\mathrm{g}}$ \\ ${ }^{a}$ ENT-Head and Neck Surgery Service, General Hospital of Concepcion, Concepcion, and \\ ${ }^{b}$ Department of Oral and Maxillofacial Radiology, Finis Terrae University School of \\ Dentistry, Santiago, Chile; 'Department of Oral and Maxillofacial Radiology, University of \\ North Carolina School of Dentistry, Chapel Hill, N.C., USA; ${ }^{d}$ Pathology Service, ${ }^{e}$ Oncology \\ Service, and ${ }^{f}$ ENT-Head and Neck Surgery Service, General Hospital of Concepcion, and \\ ${ }^{9}$ San Sebastian University, School of Medicine, Concepcion, Chile
}

\section{Key Words}

Computed tomography $\cdot$ Magnetic resonance imaging $\cdot$ Parotid gland $\cdot$ Tumor $\cdot$ Oncocytoma

\begin{abstract}
We report the case of a patient who presented to the ENT service with left facial swelling of 5 months duration. Imaging studies revealed a dense expansive mass confined to the inside of the left deep parotid lobule and moderate enhancement following contrast media injection. Subsequently, a biopsy confirmed the presence of an oncocytoma. The patient was treated with total parotidectomy, complete tumor resection and sparing facial nerve surgery. Today, the patient is disease free and has no complications.

(c) 2014 S. Karger AG, Basel
\end{abstract}

\section{Introduction}

Oncocytomas are benign epithelial tumors that most commonly occur between the sixth through the eighth decades of life with a slightly higher incidence in women. They often present as solitary slow growing painless masses, which are firm, multilobulated and mobile entities upon clinical examination. Computed tomography (CT) and magnetic resonance imaging (MRI) are the image modalities of choice, and on CT, the most common finding is a well-defined homogeneous parotid mass. On MRI, these tumors appear hypodense on T1 
Sepúlveda et al.: Oncocytoma of the Parotid Gland: A Case Report and Review of the

and T2 sequences. The preferred treatment is complete surgical excision and total parotidectomy. In addition, a follow-up MRI at 12 and 24 months is recommended to assess patient progression.

\section{Case Presentation}

A 67-year-old male presented to the ENT service with left facial swelling of 5 months duration. His medical history was unremarkable, he had no pain or cutaneous inflammatory reaction. An intraoral exam revealed swelling of the soft tissue palate, and CT and MRI imaging studies were performed to identify the nature of the swelling.

CT revealed an isodense expansive mass of $7.3 \mathrm{~cm}$ in diameter, partially confined to the inside of the left deep parotid lobule with moderate enhancement observed after intravenous contrast media injection. Hypodense areas were present.

The mass encompassed the anterior lateral and retromandibular vein, the anterior and medial pterygoid muscle, the pharyngeal mucous space, the posterior carotid space and obliteration of ipsilateral parapharyngeal fat resulting in a decrease of airway volume. The morphology of the right parotid gland and bilateral submaxillary glands was intact. The bilateral submaxillary, jugulodigastric, and left periparotid nonspecific lymph nodes were also intact (fig. 1, fig. 2).

MRI showed a large solid expansive process in the deep lobule of the left parotid gland. An isodense area was seen on T1 sequence and a mildly hyperintense on T2 (fig. 3, fig. 4). After intravenous injection of paramegnetic contrast, a moderate enhancement was observed. The mass crosses the stylomandibular space, the parapharyngeal space involving the oropharyngeal posterior wall decreasing the airway. Furthermore, it involves the anterior base of the tongue and reaches the prevertebral space (fig. 5).

A biopsy was performed on oropharyngeal submucous samples resulting in the following diagnosis: 'fragment of benign epithelial tumor consistent with oncocytoma' (fig. 6).

Following the results of the tests, it was decided that surgical excision was the best treatment with total parotidectomy, complete tumor resection and facial nerve preservation (fig. 7). At present, the patient has remained disease free with no signs of recurrence.

\section{Discussion}

Salivary gland tumors account for $3 \%$ of head and neck lesions [1] and approximately $80 \%$ of these occur in the parotid gland [2]. The majority of parotid gland tumors are located in the superficial lobe and some investigations have reported that $2-4 \%$ of parotid tumors originate from the deep lobe. A total of $80-90 \%$ of these are benign, mixed tumors and the others are adenoid cystic, mucoepidermoid, acinic cell carcinomas and lipomas [3].

The term 'oncocyte' was first introduced in 1931 by Hamperl [see reference 4]. Oncocytomas are rare tumors that constitute $0.1-1.5 \%$ of salivary gland tumors $[4,6-8]$ and only $2.3 \%$ of benign epithelial salivary gland neoplasms [5]. Oncocytomas were first described by Jaffé in 1932 [see reference 6]. The parotid gland is the most commonly involved organ accounting for $78-84 \%$ of salivary gland oncocytomas [6]. Oncocytomas are benign epithelial tumors characterized by oncocytes with eosinophilic granular cytoplasm rich in mitochondria $[3,4,9]$. Oncocytic cells are thought to originate from the transformation of epithelial cells of salivary gland ducts or acini [10]. They occur most commonly in their sixth to eighth decades and are slightly predominant in women $[6,11]$. 
Sepúlveda et al.: Oncocytoma of the Parotid Gland: A Case Report and Review of the

This tumor might be seen in other organs such as the nasal and thoracic cavities, ovaries, breast, kidney, thyroid, parathyroid, pituitary, larynx and pancreas [8, 9, 11].

The clinical presentation of oncocytomas is essentially identical to other benign salivary tumors that present as a solitary slow growing painless mass. They are firm, may be multilobulated and mobile on examination $[6,12]$. They are classified according to the new World Health Organization (WHO) classification, and histologically there are three distinct types, namely oncocytosis, oncocytoma and oncocytic carcinoma [2].

CT and conventional MRI (using T1- and T2-spin-echo sequences) are presently the image modalities of choice used in the evaluation of both palpable and nonpalpable neck lesions [12]. It is important to decide whether a mass is superficial or deep and if it affects the facial nerve. A frequently used landmark is the retromandibular vein. The facial nerve lies laterally and obliquely to this vein and can be seen on CT and MRI studies. Other considerations for the selection of additional imaging studies include involvement of adjacent tissues, perineural involvement and lymphadenopathy [1].

Technetium-99m pertechnetate scintigraphy (salivary scintigraphy) is useful to evaluate parotid gland masses. There are two ways to explain the mechanism of increasing the uptake of technetium-99m pertechnetate by oncocytoma. There is accumulation in cystic spaces due to the absence of intralobular duct. Another theory is that technetiun-99m pertechnatate can concentrate inside the tumor because the cells cannot excrete so much, meaning that the uptake is prolonged [10].

CT has been established as the first-line image modality in the assessment of major salivary gland tumors [6]. Oncocytomas and Warthin's tumors have very similar imaging features; thus, they are indistinguishable in standard CT and MR images [13]. The common CT finding of the parotid oncocytomas described in the literature is a well-defined parotid mass showing homogeneous enhancement. The reports on MRI imaging of parotid oncocytomas describe these tumors as appearing hypodense on both T1 and T2 sequences. This has been attributed to the high cellularity and low water content displaying homogeneous contrast enhancement [3, 6-8].

Complete surgical excision with radical or superficial parotidectomy are the treatments of choice $[2,6,10]$. The extent of the excision is dictated by preoperative clinical and radiological (CT, MR) examinations and intraoperative findings [6]. In addition, radiotherapy may play an important role in the management of locally advanced, unresectable, or recurrent salivary gland cancers when surgery is not feasible. Although radiotherapy can be very effective in achieving tumor shrinkage and providing symptomatic relief, curative nonoperative approaches have been challenging [14].

The use of systemic chemotherapy in advanced salivary gland cancer has in general been confined to those patients with advanced and incurable disease. Meaningful exploration of this treatment modality has been hampered by the diversity of histologic subtypes and the rarity of the disease. The scientific literature has reported results from clinical trials using a number of different chemotherapeutic agents often found in mixed populations, including patients with different histologic subtypes. Cisplatin-based regimens have been the most frequently explored, but the response rates have been modest, and the impact on survival rate has been impossible to discern.

Perhaps of greater interest in recent years has been the attempt to use our increasing understanding of the biology of these tumors to identify specific molecular targets that might be amenable to molecularly targeted therapies. Although potential molecular targets have been identified, the results using this approach have been disappointing [15-18].

The recurrence rate has been reported to be $20-30 \%$ in incomplete excision or multinodularity cases. Malignant differentiation and metastasis are rare [2, 10]. A follow-up 
Sepúlveda et al.: Oncocytoma of the Parotid Gland: A Case Report and Review of the

imaging exam, preferably an MRI at 12 and 24 months after treatment are recommended since most head and neck cancers recur within the first 2 years [19].

\section{Conclusion}

Oncocytomas are benign epithelial tumors that often occur between the sixth through the eighth decades of life. They present with facial swelling and solid solitary masses upon clinical palpation. Oncocytomas should be assessed using CT and MRI studies to evaluate the extent of their presence. Upon histological verification, a surgical approach should be considered to eradicate the tumor and remove the parotid gland. Follow-up MRI studies are recommended at 12 and 24 months after treatment since most head and neck tumors recur within the first 2 years.

\section{Disclosure Statement}

The authors have no conflicts of interest to disclose.

\section{References}

1 Day TA, Deveikis J, Gillespie MB, Joe JK, Ogretmen B, Osguthorpe JD, et al: Salivary gland neoplasms. Curr Treat Options in Oncol 2004;5:11-26.

2 Vlachaki E, Tsapas A, Dimitrakopoulos K, Kontzoglou G, Klonizakis I: Parotid gland oncocytoma: a case report. Cases J 2009;2:6423.

-3 Özcan C, Talas D, Görür K, Aydin Ö: Incidental deep lobe parotid gland oncocytic neoplasm in an operated larynx cancer patient. Oral Oncol Extra 2006;42:235-240.

4 Yoshihara T, Satoh M, Yamamura Y: An ultrastructural study of oncocytoma and oncocytic carcinoma of the parotid gland. Med Electron Microsc 1997;30:31-36.

5 Sakthikumar KRV, Mohanty S, Dineshkumar K: Solitary oncocytoma of the submandibular salivary gland in an adolescent female: a case report. Indian J Otolaryngol Head Neck Surg 2007;59:171-173.

-6 Tan TJ, Tan TY: CT features of parotid gland oncocytomas: a study of 10 cases and literature review. AJNR Am J Neuroradiol 2010;31:1413-1417.

7 Sakai E, Yoda T; Shimamoto H, Hirano Y, Kusama M, Enomoto S: Pathologic and imaging findings of oncocytoma in the deep lobe of the left parotid gland. Int J Oral Maxillofac Surg 2003;32:563-565.

-8 Shellenberger TD, Williams MD, Clayman GL, Kumar AJ: Parotid gland oncocytosis: CT findings with histopathologic correlation. AJNR Am J Neuroradiol 2008;29:734-736.

-9 Lauro CF, Neuhauser TS, Gill S, Peti J: Radiation-induced oncocytic carcinoma of the parotid in a 66-year-old woman. J Radiat Oncol 2012;1:305-309.

10 Kasai T, Motoori K, Hanazawa T, Nagai Y, Ito H: MR imaging of multinodular bilateral oncocytoma of the parotid gland. Eur J Radiol Extra 2007;63:97-100.

11 Watanabe T, Yoshida Y, Yamamoto 0: Oncocytoma of the parotid gland presenting as a subcutaneus tumor. Eur J Dermatol 2011;21:273-274.

12 Srinivasan A, Dvorak R, Perni K, Rohrer S, Mukherji SK: Differentiation of benign and malignant pathology in the head and neck using 3T apparent diffusion coefficient values: early experience. AJNR Am J Neuroradiol 2008;29:40-44.

13 Araki Y, Sakaguchi R: Synchronous oncocytoma and Warthin's tumor in the ipsilateral parotid gland. Auris Nasus Larynx 2004;31:73-78.

14 Armstrong JG, Harrison LB, Thaler HT, et al: The indications for elective treatment of the neck in cancer of the major salivary glands. Cancer 1992;69:615-619.

15 Papaspyrou G, Hoch S, Rinaldo A, et al: Chemotherapy and targeted therapy in adenoid cystic carcinoma of the head and neck: a review. Head Neck 2011;33:905-911.

16 Surakanti SG, Agulnik M: Salivary gland malignancies: the role for chemotherapy and molecular targeted agents. Semin Oncol 2008;35:309-319.

$\checkmark 17$ Hotte SJ, Winquist EW, Lamont E, et al: Imatinib mesylate in patients with adenoid cystic cancers of the salivary glands expressing c-kit: a Princess Margaret Hospital phase II consortium study. J Clin Oncol 2005;23:585-590. 


\section{Case Reports in Oncology}

\begin{tabular}{l|l}
\hline Case Rep Oncol 2014;7:109-116 \\
\hline DOI: 10.1159/000359998 & $\begin{array}{l}\text { @ 2014 S. Karger AG, Basel } \\
\text { www.karger.com/cro }\end{array}$ \\
\hline
\end{tabular}

Sepúlveda et al.: Oncocytoma of the Parotid Gland: A Case Report and Review of the Literature

18 Agulnik M, Cohen EW, Cohen RB, et al: Phase II study of Lapatinib in recurrent or metastatic epidermal growth factor receptor and/or erbB2 expressing adenoid cystic carcinoma and non adenoid cystic carcinoma malignant tumors of the salivary glands. J Clin Oncol 2007;25:3978-3984.

19 Gillespie MB, Albergotti WG, Eisele DW: Reurrent salivary gland cancer. Curr Treat Options Oncol 2012;13:58-70.

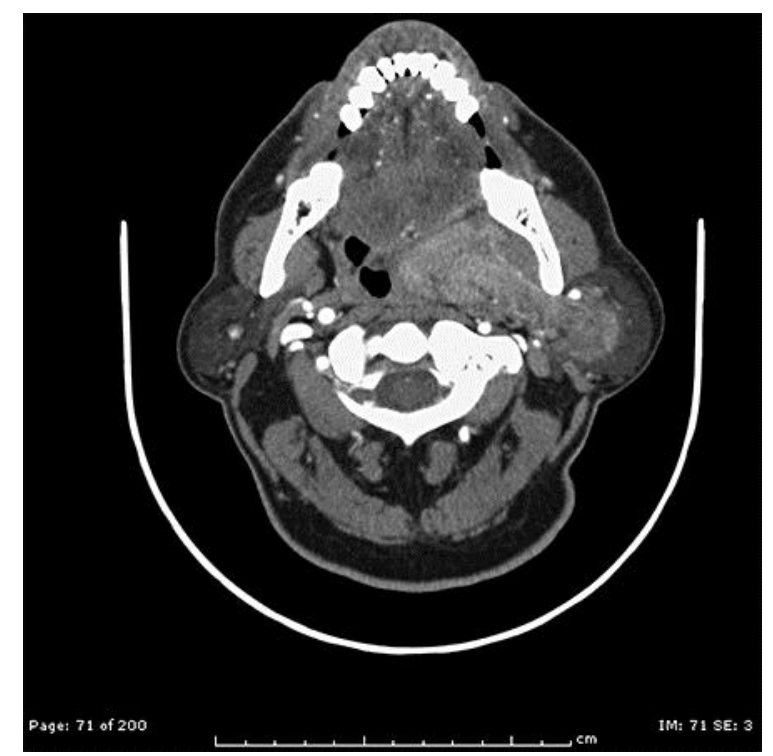

Fig. 1. A mass is seen in the deep parotid lobule with moderate enhancement after intravenous contrast injection. The retromandibular vein is displaced anteriorly and laterally.

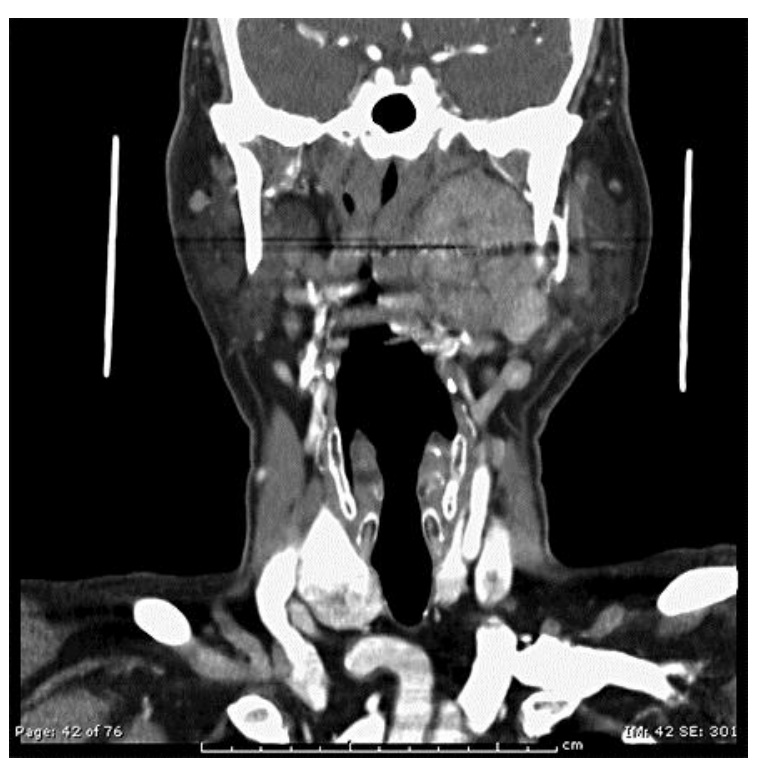

Fig. 2. Decrease of the upper airway space. 


\section{Case Reports in Oncology}

Sepúlveda et al.: Oncocytoma of the Parotid Gland: A Case Report and Review of the Literature

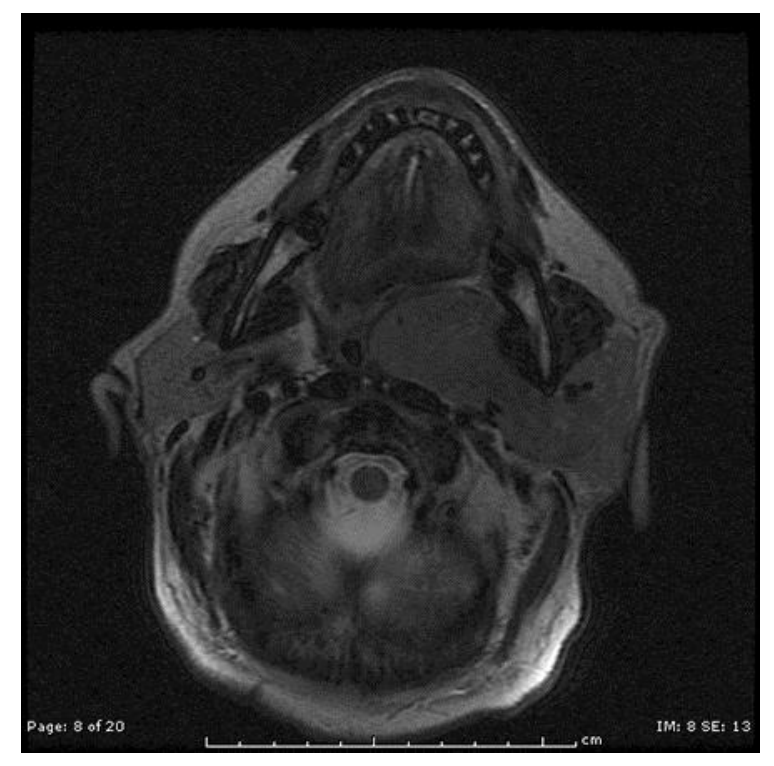

Fig. 3. T1 sequence of an isointense solid mass.

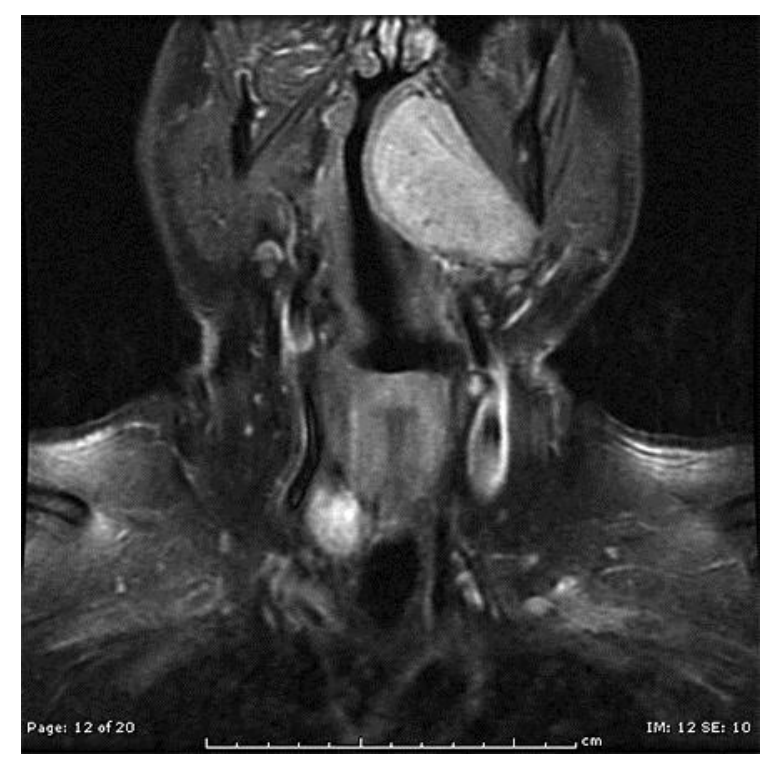

Fig. 4. Stir sequence of a mildly hyperintense mass. 


\section{Case Reports in Oncology}

Sepúlveda et al.: Oncocytoma of the Parotid Gland: A Case Report and Review of the Literature

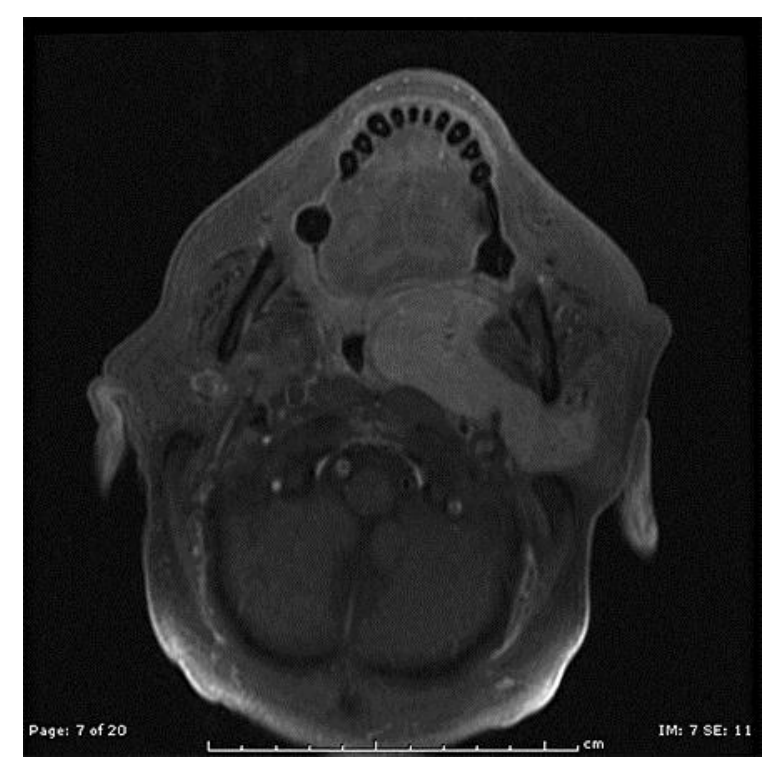

Fig. 5. T1 FSGD sequence involves the anterior, left base of the tongue and reaches the prevertebral space.

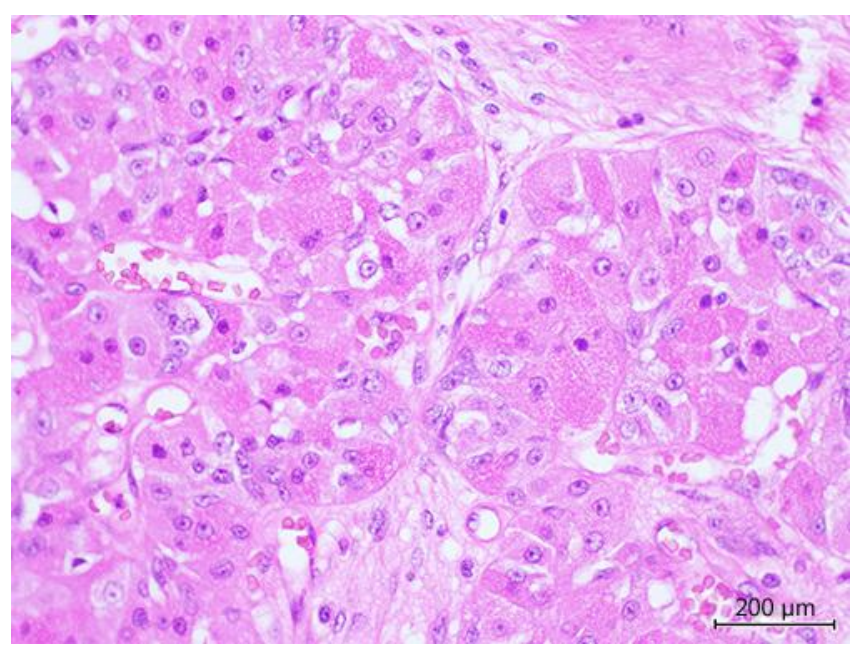

Fig. 6. HE stain. 


\section{Case Reports in Oncology}

Case Rep Oncol 2014;7:109-116

DOI: 10.1159/000359998

Sepúlveda et al.: Oncocytoma of the Parotid Gland: A Case Report and Review of the Literature

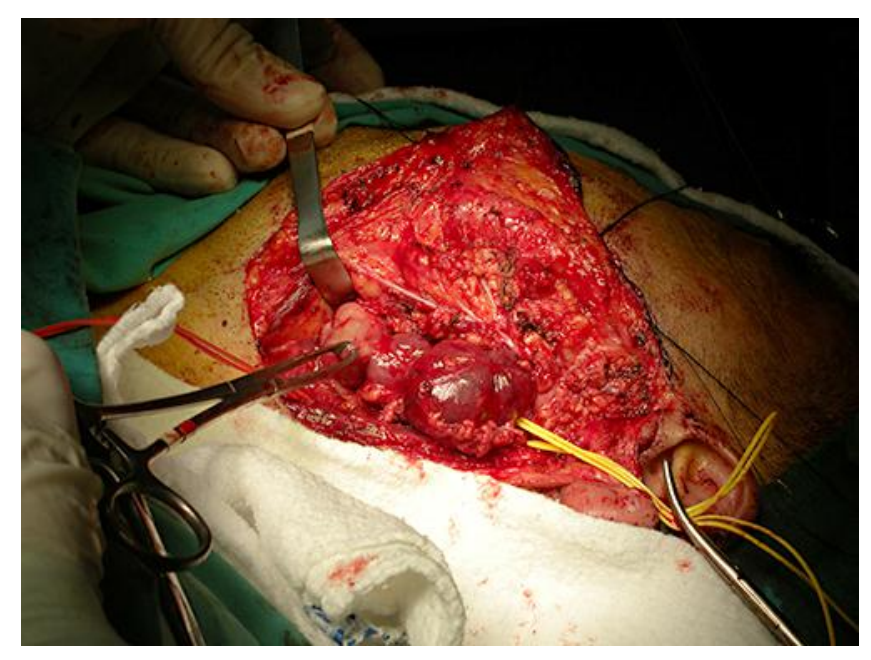

Fig. 7. Completed tumor resection and facial nerve preservation. 